\title{
Europeização e Reforma do Setor de Segurança nos Estados Balcânicos Ocidentais (2000-2014)1
}

\author{
Europeanization and Security Sector Reform \\ in Western Balkan States (2000-2014)
}

Marília Bortoluzzi Severo*

\section{Resumo}

Este artigo faz parte de uma pesquisa doutoral sobre a relação entre o processo de adesão de Croácia, Bósnia-Herzegovina, Macedônia e Sérvia à União Europeia (UE) e a reforma do setor de segurança (security sector reform - SSR) desses países. Como decorrência do exercício do poder normativo europeu, é possivel sugerir que o processo de adesão à UE impactou ou tem impactado, de algum modo, na reforma do setor securitário dos Estados balcânicos ocidentais. Sendo que um dos principais interesses da UE em relação aos Bálcãs Ocidentais refere-se à segurança da região (e, por consequência, à sua própria segurança), o processo de expansão interfere direta ou indiretamente nas reformas securitárias que cada Estado tem executado. Afirma-se, assim, que a UE trata da sua segurança e de seus membros através de uma política de expansão condicionada e institucionalizada pela entidade. O presente estudo, então, analisa e mostra a existência de uma relação significativa entre o processo de europeização de políticas de segurança, promovido dentro do quadro da expansão europeia, e as reformas securitárias ocorridas na Bósnia-Herzegovina, na Croácia, na Macedônia e na Sérvia, no período 2000-2014.

Palavras-chave: União Europeia; Bálcãs Ocidentais; Reforma do Setor de Segurança; Europeização; Processo de Adesão.

\begin{abstract}
This article is part of doctoral research about the relation between the accession process of Croatia, Bosnia and Herzegovina, Macedonia and Serbia to the European Union (EU) and the security sector reform (SSR) of these countries. As a result of the exercise of European normative power, it is possible to suggest the process of accession to the EU has impacted in any way in reforming the security sector in the Western Balkan states. Since one of EU's main interests in Western Balkans concerns the security of the region (and therefore the guarantee of its own security), the expansion process interferes directly or indirectly in the security reforms each state has been promoting. Nonetheless, we can say the EU takes care of its safety and that of its members through a policy of expansion conditioned and institutionalized by it. This study therefore analyzes and shows the existence of a significant relation between the europeanization process of security policies, promoted within the framework of EU's expansion, and the security reforms that have been taken place in Bosnia and Herzegovina, Croatia, Macedonia and Serbia, in the 2000-2014 years.

Keywords: European Union; Western Balkans; Security Sector Reform; Europeanization; Accession Process.

1 Este artigo faz parte da pesquisa doutoral da autora, constituída na tese de doutorado Integração e segurança nas relações entre a União Europeia e os Bálcãs Ocidentais (2000-2014), defendida no Programa de Pós-Graduação em Ciência Política da Universidade Federal do Rio Grande do Sul. 0 artigo foi apresentado no $5^{\circ}$ Encontro Nacional da ABRI, na Área Temática Segurança Internacional, Estudos Estratégicos e Política de Defesa. Ainda, a autora agradece as contribuições dos Professores Carlos Schmidt Arturi e Clarissa Franzoi Dri na revisão deste manuscrito.

* Pós-Doutoranda no Programa de Pós-Graduação em Relações Internacionais (PPCRI) da Universidade Federal de Santa Catarina (UFSC).
\end{abstract}




\section{Introdução}

Em termos de relações com países vizinhos, um dos grandes desafios para a União Europeia (UE) é, sem dúvida, a região dos Bálcãs Ocidentais, seja por ter sido palco de diversas guerras, seja por abrigar Estados com dificuldades econômicas e políticas. Tendo isso em vista, tal área constitui um fator de importância estratégica e geopolítica para a segurança interna e externa da UE. Desse modo, a aproximação desse ator regional aos Estados balcânicos ocidentais merece um exame de suas intenções e perspectivas.

Este estudo parte do pressuposto de que, através do seu poder normativo, a UE exerce uma força de atração irresistivel sobre os Estados balcânicos candidatos à adesão, de modo que eles aceitam as regras do processo e cooperam com esta política de expansão. Poder normativo, aqui, é tratado como a capacidade de promover certas normas e valores para além das suas fronteiras, de maneira a moldar ou influenciar interesses, perspectivas e decisões alheias. No que se refere ao tema desta proposta, o processo de adesão criado para os Bálcãs Ocidentais, cujos objetivos são consolidar a democracia, a economia de mercado, o respeito aos direitos humanos, dentre outros princípios, pode ser considerado uma forma de ação do poder normativo europeu, na medida em que os Estados balcânicos são impelidos a adotar estes valores para cumprir os requisitos do processo.

Quanto ao domínio da segurança, o bloco europeu expressa o seu poder normativo dentro do processo de adesão através da europeização das propostas de reforma do setor securitário (security sector reform - SSR) dos países balcânicos ocidentais. Com efeito, o fenômeno europeizante exterioriza de forma clara o poder normativo europeu, por se configurar em um processo de construção, difusão e institucionalização de normas, valores e procedimentos, os quais são deliberados pela UE e inseridos nas políticas nacionais (RADAELLI, 2003). Logo, a ideia é expor que, no exercício de seu poder normativo, a UE coopta os Estados balcânicos ocidentais à utilização de valores, normas e práticas de âmbito securitário, os quais são definidos por ela no quadro do processo de adesão.

A metodologia deste trabalho parte de uma pesquisa qualitativa sobre os incentivos da UE às reformas securitárias na região balcânica ocidental e de uma análise de entrevistas com funcionários da Comissão Europeia e das representações nacionais responsáveis pelo processo de adesão dos quatro Estados objeto de estudo. Através do método de entrevista semiestruturada (SELLTIZ, 1987), foram entrevistadas sete autoridades envolvidas no processo de admissão à UE, sendo três delas responsáveis pelas perspectivas nacionais, e quatro funcionários oficiais da UE.

A partir disso, busca-se responder à seguinte questão de pesquisa: nas políticas e práticas de reforma do setor securitário, como os Estados dos Bálcãs Ocidentais respondem aos incentivos da europeização que ocorre através do processo de adesão? Para tanto, é apresentada uma seção explicativa da abordagem conceitual deste estudo, isto é, da relação entre processo de adesão, europeização e reforma do setor de segurança, seguida de quatro subseções dedicadas a cada um dos Estados por ora analisados: Bósnia-Herzegovina, Croácia, Macedônia e Sérvia. Tais países foram selecionados para representar a região dos Bálcãs Ocidentais com base em sua importância em termos de segurança para a UE e também em função da evolução particular de cada um no processo de adesão, por se enquadrarem em diferentes etapas. 


\section{A europeização das SSR no contexto do processo de expansão da UE}

Considerando a capacidade da UE de atuar em questões securitárias, vários temas não tradicionais desse domínio passaram a formar a compreensão ampla e transversal do que tal ator internacional entende por segurança no decorrer da década de 1990. Embora o acervo comunitário², na forma como é posto para os candidatos à adesão, não mencione, especificamente, a definição de segurança para a UE, a Estratégia de Segurança Europeia (ESE), aprovada pelo Conselho Europeu em 2003, é o marco conceitual da identificação de ameaças no quadro da política europeia securitária e defensiva (EUROPEAN UNION, 2003).

No contexto do processo de adesão, os temas securitários são tratados dentro do Processo de Estabilização e Associação (Stabilization and Association Process - SAP) nos mais diversos capítulos. Adotando uma abordagem transversal de sistema ou setor de segurança, fundamentada nas orientações da Organização para a Cooperação e Desenvolvimento Econômico (OCDE), a UE centra o debate dessas questões no envolvimento de quatro esferas de atuação: agentes de segurança essenciais, incluindo as instituições de aplicação da lei; gestão de segurança e órgãos de fiscalização; instituições de justiça; e forças de segurança não oficiais.

A partir disso, os assuntos relacionados à temática securitária podem ser analisados no processo de adesão à UE através do espectro teórico e prático da reforma do setor de segurança. A ferramenta analítica da SSR tem sido utilizada, por atores de promoção do desenvolvimento e analistas sobre o tema, para dar conta das atividades de reforma dos elementos do setor público responsáveis pela provisão de segurança externa e interna (HÄNGGI, 2004), que correspondem às esferas de atuação acima mencionadas.

De fato, é possivel pensar nesse aporte analítico como um mecanismo conceitual prismático que abrange as ações ligadas às transformações pelas quais organismos e serviços públicos devem passar para atuar com mais eficácia e eficiência nas questões de segurança. A literatura (HÄNGGI, 2004; CAPARINI, 2006) tem convergido para a compreensão de que a SSR tem por foco primordial um setor securitário que é disfuncional, isto é, incapaz de prover a segurança interna e/ou externa dos agentes a que pertence, ou que constitui a própria fonte de insegurança.

Confirmando esse entendimento, o "Documento Conceitual para o Apoio da Comunidade Europeia na Reforma do Setor de Segurança" (COMMISSION OF THE EUROPEAN COMMUNITIES, 2006) coloca a SSR como um valor comum da ação externa da UE em sua atuação global. $\mathrm{Na}$ visão do bloco europeu, a SSR reflete a natureza multidimensional da concepção de segurança, o que a torna um instrumento essencial na prevenção de conflitos, construção da paz e desenvolvimento sustentável. Dessa maneira, a Comissão Europeia salienta que o foco da SSR não está nos serviços individuais, mas, sim, no funcionamento geral do sistema de segurança como parte da governabilidade do setor público. Sobretudo, a SSR parece fornecer uma abordagem coerente para o desenvolvimento estatal (RYAN, 2009).

20 acervo, conhecido como acquis communautaire, é a base comum de direitos e obrigações que liga os Estados membros à UE e entre si. Além de normas de Direito comunitário propriamente dito, o acquis inclui todos os atos jurídicos e contratuais relacionados à UE, bem como a jurisprudência do Tribunal Europeu e acordos e tratados entre a UE e qualquer outro ator internacional (Estados, organismos internacionais, organismos não governamentais, etc.). 
Ainda nesta publicação, a Comissão deixa claro que essa atividade faz parte do quadro do enlargement, aqui traduzido como alargamento ou processo de expansão, estando, assim, intimamente ligada ao SAP. Logo, ressaltando que a implementação da SSR pode variar conforme os contextos domésticos, a Comissão recomenda que ela seja inserida em seis estratégias de políticas, entre elas, a de expansão (COMMISSION OF THE EUROPEAN COMMUNITIES, 2006). A Comissão também esclarece que o processo de adesão é um importante incentivo às reformas, afinal, a SSR está incluída, de alguma forma, nos Critérios de Copenhague ${ }^{3}$ - mesmo que não expressamente. Isso porque o quadro da ação europeia em termos de SSR gira em torno de temas que são abrangidos pela condicionalidade do SAP (COMMISSION OF THE EUROPEAN COMMUNITIES, 2006).

Não se pode negar que o quadro de segurança que a UE oferece é um ponto de partida interessante para a criação ou a reformatação de serviços securitários nos Bálcãs Ocidentais. Os países dessa região sofreram os reveses de situações de conflito e de transição de regime, o que gerou a necessidade de reestruturação dos setores de segurança nacionais e, inclusive, de criação de serviços nessa esfera. E, por causa disso, a SSR tem sido o instrumento utilizado pela UE para o alcance de transformações abrangentes relacionadas aos atores e atividades de segurança, dada a sua aplicabilidade a contextos frágeis.

No entanto, ainda que não exista uma política oficial de SSR da UE para os Bálcãs Ocidentais, é viável questionar como ocorre a circulação de ideias, políticas, normas e modelos institucionais no âmbito desse processo. A compreensão da circulação e da transferência nas SSR pode ser feita através do fenômeno de europeização que deriva da expansão da UE ${ }^{4}$. A dinâmica da europeização permite enquadrá-la como um processo de construção, difusão e institucionalização de regras formais e informais, paradigmas políticos, práticas e crenças comuns, os quais são consolidados na esfera da UE e, posteriormente, incorporados na lógica do discurso doméstico (RADAELLI, 2002). Ou seja, é a assimilação de diretrizes e práticas políticas externas - no caso, da UE - no âmbito da política interna.

Com efeito, a realidade estrutural do setor securitário dos Estados balcânicos ocidentais confirma a importância da UE na região, tendo em vista o papel dessa na formatação de tais serviços e o recente processo de reconstrução estatal de tais países - lembre-se que o surgimento de um aparato estatal institucionalizado para cada país somente ocorreu com a desintegração da Iugoslávia, a partir de 1991. Por outro lado, a UE emprega esforços de europeização das atividades de segurança desses países na intenção de manter os Bálcãs Ocidentais como uma esfera de influência enquanto ainda não são Estados membros, haja vista que seus principais membros são historicamente dominantes na dinâmica de poder do continente europeu.

3 Os Critérios de Copenhague, adotados pela UE no encontro do Conselho Europeu em 1993, configuram as diretrizes primárias do processo de expansão e podem ser resumidos nos seguintes requisitos a serem preenchidos pelo Estado que deseja aderir à UE: a) presença de instituições estáveis que garantam a democracia, o Estado de Direito, os direitos humanos e a proteção de minorias; b) existência de economia de mercado plenamente operacional e que possa responder às forças da concorrência e de mercado internamente; e c) compromisso e habilidade de implementar as obrigações decorrentes do status de Estado membro.

4 Segundo argumenta Radaelli (2002), a europeização não pode ser vista como um processo de integração política - ela é, na verdade, um efeito da integração, e não uma causa desta. 
De início, a preocupação da UE quanto à SSR nos Bálcãs Ocidentais estava relacionada a questões de gestão civil de crises, reforma do Judiciário e da segurança interna, reforma da polícia, cooperação regional e gestão das fronteiras e da migração (COMMISSION OF THE EUROPEAN COMMUNITIES, 2006). Nesse sentido, por volta de 2006, a Comunidade Europeia estava engajada no estabelecimento de uma autoridade de segurança nacional nas ex-repúblicas iugoslavas, bem como nas reformas promovidas com o suporte do instrumento financeiro do processo de adesão à UE.

Além disso, o apoio da UE nas SSR balcânicas também enfocava a construção de instituições de direitos humanos estabelecidas no quadro do Acordo de Dayton ${ }^{5}$ e na cooperação regional em assuntos judiciais, compartilhamento de informações policiais e gestão de fronteiras. Por fim, a gestão financeira das despesas relacionadas às SSR estava sendo apoiada pela UE tanto através de projetos quanto por meio da prescrição de reformas nos ministérios das finanças e nos sistemas de auditoria de cada país candidato.

A perspectiva da UE centrada nas questões mais tradicionais de segurança faz sentido ao se considerar que o setor securitário dos países balcânicos ocidentais é, em geral, fragmentado, subdesenvolvido (no caso das forças policiais) ou superdesenvolvido (no caso das forças militares), excessivamente politizado e estruturado com base em divisões étnicas ou religiosas (CAPARINI, 2006). Tendo isso em conta, tal panorama exige que as SSR envolvam um componente securitário de estabilização e consolidação da paz. A herança de situações de conflito e de regimes autoritários torna a tarefa de SSR mais complicada do que em outros contextos. Ter o controle das atividades securitárias, nesse sentido, é fundamental, sobretudo porque a reconstrução estatal é um desafio permanente.

A persistência de fracas capacidades estatais, em especial no que se refere à coerção, somada à corrupção e a poderes privados paralelos, enfraquece a autoridade do Estado, transformando tais países em um terreno fértil para a criminalidade. Confirmando esse argumento, Stojarova (2007) sustenta que o crime organizado nos Bálcãs é um fenômeno recente, que evoluiu durante as guerras de dissolução iugoslava devido aos bloqueios econômicos, à fraqueza estatal e ao vácuo legal que imperava naquele momento. Em decorrência disso, nos Estados balcânicos contemporâneos, o crime organizado está facilmente inserido nas instituições estatais, através da corrupção no setor público.

Por outro lado, os processos de europeização atuais mais relevantes na reforma do setor de segurança nos Bálcãs Ocidentais estão inseridos de modo institucionalizado no processo de adesão à UE. O SAP recomenda e monitora a reforma nas atividades de policiamento, defesa, inteligência e judiciárias. Algumas dessas ações são sugeridas; enquanto outras são obrigatórias, conforme o Estado a que se refere. Também varia o incentivo de maior peso à produção de mudanças, de acordo com o setor em questão e o país: a adesão à UE (no caso da esfera policial, de governança e de defesa civil) ou a admissão na Organização do Tratado do Atlântico Norte OTAN (no caso de questões militares).

A adesão à OTAN funciona bastante como estímulo às reformas dos serviços de defesa militar - e também porque as exigências deste organismo são consideradas mais fáceis de

5 Tratado que pôs fim ao conflito de dissolução da Bósnia-Herzegovina, assinado em 14 de dezembro de 1995. 
serem alcançadas do que as da UE. De fato, o cumprimento dos requisitos estabelecidos para a admissão na OTAN tem levado à modernização das forças militares e ao controle democrático destas. No entanto, isso acaba por tornar a defesa nacional subordinada aos princípios e interesses da OTAN, que nem sempre se coadunam com as necessidades de Estados de passado autoritário e conflituoso (CAPARINI, 2006).

Nos próximos itens, essas e outras questões serão analisadas em relação a cada país objeto de pesquisa - Bósnia-Herzegovina, Croácia, Macedônia e Sérvia, à luz das reformas securitárias incentivadas pela UE no contexto do processo de adesão.

\section{Bósnia-Herzegovina}

Neste estudo, informações foram coletadas a respeito do cenário da esfera securitária bósnia através de entrevistas realizadas na Delegação da UE para a Bósnia-Herzegovina e no Diretório para a Integração Europeia, escritório bósnio responsável pelo andamento do processo de admissão à UE. A prevalência de ações que se referem aos temas da ESE no país foi ressaltada, mesmo que, em termos de gestão securitária, o panorama bósnio seja mais complicado de se lidar do que outros Estados balcânicos. Existem diversas iniciativas de segurança sendo executadas pela UE, principalmente quanto à segurança das fronteiras e ao combate ao crime organizado e à corrupção (DELEGAÇÃO DA UNIÃO EUROPEIA PARA A BÓSNIA-HERZEGOVINA E REPRESENTAÇÃO ESPECIAL DA UNIÃO EUROPEIA NA BÓSNIAHERZEGOVINA, 2014).

No que concerne à ligação entre o processo de adesão à UE e as reformas do setor securitário, ambas as representações da UE e da Bósnia-Herzegovina foram categóricas em confirmar a existência de conexão entre esses dois fenômenos. Deve ser destacado que a reforma dos serviços policiais foi uma exigência da UE para a assinatura do Acordo de Estabilização e Associação (Stabilization and Association Agreement - SAA), enquanto que as transformações do setor defensivo são uma demanda para a admissão à OTAN (DIRETÓRIO PARA A INTEGRAÇÃO EUROPEIA, 2014). Por este motivo, é possível visualizar uma ligação direta entre algumas mudanças do setor de segurança e o processo de integração europeia.

Nesse sentido, embora o processo formal de adesão da Bósnia ainda não tenha começado, visto que o país se encontra em fase de pré-adesão6, a UE estabeleceu algumas condições relacionadas à segurança, tanto para a assinatura e vigência do SAA quanto para a aceitação da candidatura bósnia. Entre elas, estão a gestão de questões de liberalização de vistos, a criação de uma agência anticorrupção e a administração e controle adequado das fronteiras. Com efeito, é possível verificar grandes avanços nestes assuntos e na troca de informações entre sistemas policiais, em especial quando as autoridades de todos os níveis de governo trabalham coletivamente (DELEGAÇÃO DA UNIÃO EUROPEIA PARA A BÓSNIA-HERZEGOVINA E REPRESENTAÇÃO ESPECIAL DA UNIÃO EUROPEIA NA BÓSNIA-HERZEGOVINA, 2014).

6 Até fevereiro de 2016, a Bósnia-Herzegovina mantinha o status de Candidato em Potencial, isto é, o processo de negociações para a adesão não havia sido iniciado. Destaca-se que o SAA assinado em junho de 2008 somente entrou em vigência em junho de 2015 , em função da dificuldade do alcance de diversos requisitos impostos pela UE. Em 15 de fevereiro de 2016, o país submeteu sua candidatura à adesão à UE - no momento em que esta for aceita, a Bósnia-Herzegovina se tornará um Estado Candidato. 
Como Dursun-Ozkanca e Vandemoortele (2012) assinalam, a criação de duas entidades separadas na Bósnia pós-Dayton (a Federação da Bósnia-Herzegovina e a República Srpska) acabou originando dois exércitos, polícias e serviços de inteligência desagregados, com a consequente divisão sendo replicada em outras áreas. Então, enquanto os criminosos podem transitar e praticar crimes de uma jurisdição para a outra, a polícia e o Judiciário não têm a mesma prerrogativa, o que dificulta a tomada de ações nesse domínio. Como se pode perceber, a estrutura constitucional bósnia é um forte obstáculo à execução da lei, o que apenas pode ser resolvido através do empenho coordenado entre as esferas de governo.

De fato, em um contexto que mistura um cenário pós-autoritário e pós-conflito, em que há não apenas um déficit democrático, mas securitário, a tarefa de promoção da SSR é menos difícil quando existe um esforço conjunto, de maneira a evitar possiveis pontos de veto nos mais diversos níveis. Considerando que a Bósnia-Herzegovina apresenta uma estrutura governativa complexa, com, ao menos, quatorze esferas de governo, a tendência de sucesso das reformas securitárias diminui à medida que aumentam os níveis e atores que interferem no processo. Logo, qualquer tentativa de mudança nesse setor precisa considerar essa conjuntura.

A UE tem incentivado as transformações dos serviços securitários, seja por meio da utilização de instrumentos comunitários do alargamento na promoção da SSR com foco no reforço da capacidade institucional (institution-building), seja através da Missão de Polícia da UE (European Union Police Mission - EUPM), que tratou da reforma policial, no período 2003-2012 (DURSUN-OZKANCA; VANDEMOORTELE, 2012). Contudo, o exame dos assuntos que tocam os Capítulos 23, 24 e $31^{7}$ do acervo comunitário no Relatório de Progresso de 2014, elaborado pela Comissão Europeia, indica que o tratamento destes itens tem variado entre progresso e paralisia.

Há pouca evolução prática nas reformas que objetivam a redução da corrupção, permanecendo isso mais preocupante nos serviços públicos e no acesso a empregos; porém, o maior desafio se encontra no setor policial (EUROPEAN COMMISSION, 2014a). O comprometimento da UE no fomento das reformas dessa esfera é manifesto; o que parece faltar é a apropriação das ações de mudança pelos atores locais. Por volta de 2008, a reforma do setor policial foi definida pela UE como a principal condição para a assinatura do SAA. A partir disso, a União passou a orientar a formulação e adaptação de políticas policiais, com o apoio de um Alto Representante ${ }^{8}$, o qual se encarregava de impor a legislação e demitir as autoridades que procuravam obstruir o processo.

No entanto, como processo top-down, as reformas dos serviços policiais não foram suficientemente incorporadas e apropriadas pelas autoridades bósnias, que não viam benefícios na adoção de medidas reformistas tão estritas quanto as propostas por UE e Alto Representante. Nesse sentido, para Dursun-Ozkanca e Vandemoortele (2012), o processo de reestruturação policial configurou um episódio de grande fracasso na implementação da SSR policial, embora certos elementos indiquem alguma adaptação do ambiente político bósnio a essa dinâmica, como a cooperação em procedimentos policiais técnicos9 .

7 Os Capítulos 23, 24 e 31 do SAP correspondem aos itens "Poder judiciário e direitos fundamentais"; "Justiça, liberdade e segurança"; e "Política externa, de segurança e defesa", respectivamente.

8 Emissário da UE com a missão específica de supervisionar a implementação civil do Acordo de Dayton.

9 Como exemplo, é possível citar o Projeto de Gestão Prisional Eficiente, financiado pela UE, com a meta de tornar o sistema prisional mais eficiente, transparente e humanitário (DIRECTORATE FOR EUROPEAN INTEGRATION, 2015). 
Nos dias atuais, urge a necessidade de desenvolver e garantir a aplicação do quadro legislativo que rege o policiamento. Apenas recentemente a Federação e os cantões promoveram iniciativas no sentido do alinhamento de suas respectivas legislações sobre temas policiais. A ausência de cooperação e coordenação institucional entre os diferentes níveis de organismos de policiamento (central, entitário, cantonista e municipal) tem impedido a prestação eficaz dos serviços policiais (EUROPEAN COMMISSION, 2014a).

O desafio está no fato de que a elite bósnia, que poderia se apoderar do processo de reformas, é a mesma que depende da conjuntura atual (isto é, de ausência de centralização, fracas capacidades estatais, violência, corrupção e divisões étnicas) para sobreviver. Com isso, a imposição externa de mudanças, obviamente, não é bem recebida. Em síntese,

Os esforços da UE em promover a reestruturação da polícia na Bósnia constituem um excelente caso para testar o poder e as limitações do incentivo de adesão à UE para os países candidatos e para examinar o processo de europeização na Bósnia. 0 fracasso em promover a reforma da polícia na Bósnia pode ser explicado por referência à estratégia da UE (condições, recompensas, credibilidade e legitimidade) e aos obstáculos internos ao cumprimento da condicionalidade da UE. Retratado como uma entre outras reformas "técnicas" a serem realizadas pelo país antes da assinatura do Acordo de Estabilização e Associação (AEA), a reforma da polícia mostrou ser mais uma questão política do que era anteriormente reconhecido pela Comissão Europeia. (JUNCOS, 2011, p. 368).

Quanto às mudanças no setor defensivo, estas se devem, quase que exclusivamente, à pressão dos atores internacionais. O protagonismo nas reformas da defesa esteve a cargo da OTAN, sendo importante ressaltar que tais transformações, em última instância, coadunam-se com os princípios e valores da UE, já que ambas possuem fundamentos comuns em termos teóricos de defesa. Como o bloco europeu evita a construção de um exército militar próprio, em termos práticos, a Organização euro-atlântica funciona como o seu braço armado - daí é justificável que ela esteja mais envolvida nas reformas do setor militar do que a própria UE.

Por fim, é viável afirmar que os principais obstáculos às reformas securitárias na Bósnia ainda são a ausência de apropriação da SSR pelos atores internos, o que provoca a falta de apoio e/ou empenho político, e os arranjos constitucionais estabelecidos no Acordo de Dayton, que tornam o panorama institucional mais complexo e sujeito a pontos de veto. Apesar disso, os processos europeizantes de SSR aparentam estar conexos ao processo de adesão à UE, seja de modo direto (ao constituírem precondições para algum passo do SAP) ou indireto (quando a aproximação de padrões europeus se torna um incentivo para mudanças).

\section{Croácia}

Os esforços de mudanças em termos securitários na Croácia se concentraram na ideia de preencher rapidamente os requisitos de adesão à UE e à OTAN. Em entrevista com a representação croata da Comissão Europeia, foi possivel confirmar que as reformas de segurança e defesa foram promovidas em função disso (COMISSÃO EUROPEIA COM REPRESENTAÇÃO NA CROÁCIA, 2014). É intuitivo, então, relacionar as transformações securitárias croatas e a 
integração europeia: as reformas foram aumentando à medida que os anos se passavam e o processo de adesão à UE progredia.

Os temas de segurança mais citados no processo de adesão croata referiram-se à participação do país em missões de paz, migração, gestão conjunta de fronteiras e recebimento de asilados. Desde antes da adesão, a principal participação da Croácia nas ações securitárias relacionadas à UE já era o engajamento em atividades de manutenção da paz (peacekeeping), visto os croatas serem considerados profissionais especialistas em temas desse domínio (COMISSÃO EUROPEIA COM REPRESENTAÇÃO NA CROÁCIA, 2014). Porém, pelo ponto de vista da representação croata, questões de segurança não tiveram tanto destaque no quadro de adesão, pelo fato de a UE comportar-se como um poder brando (soft power), o que deixaria tais assuntos sob responsabilidade da OTAN (COMISSÃO EUROPEIA COM REPRESENTAÇÃO NA CROÁCIA, 2014).

Após a admissão à UE10, o grande desafio é a continuidade do ritmo e da vontade política quanto às reformas em direção aos padrões estabelecidos pela União. O Estado parece ter superado grande parte dos paradigmas originados pela combinação de contextos pós-autoritário e pós-conflito, como o colapso institucional, bolsões de resistência armada, a disparidade entre a atuação estatal e a da sociedade civil e a inadequação do aparato securitário. No entanto, o último relatório de monitoramento sobre a Croácia publicado pela Comissão Europeia admite que o país deve continuar executando reformas para desenvolver os valores europeus (EUROPEAN COMMISSION, 2013).

A manutenção da efetividade do Estado de Direito e a luta contra a corrupção podem ser elencadas como as maiores ameaças à Croácia pós-adesão. Tais assuntos merecem ênfase por terem sido objeto da SSR inserida no âmbito da europeização das políticas croatas que ocorreu no SAP. A corrupção na esfera pública permanece um desafio, mesmo havendo uma avaliação positiva no Relatório de Progresso de 2011 sobre a adoção do quadro institucional e legal de um plano anticorrupção (as leis aprovadas sobre esses pontos estavam em conformidade com a legislação do acervo comunitário; contudo, parte delas não está em vigor até hoje). Houve a criação de um Escritório para o Combate à Corrupção e ao Crime Organizado, através de um projeto da UE para o assessoramento dessas questões, mas sua atuação enfrenta obstáculos políticos e legais (EUROPEAN COMMISSION, 2011a).

A corrupção é um dos problemas relacionados às forças policiais croatas, assim como a sua politização e o uso excessivo da força e da violência. Essa polícia é, reconhecidamente, uma das mais truculentas dos Bálcãs Ocidentais (GRILLOT, 2008). Por causa disso, as organizações internacionais engajaram-se durante a década de 2000 no treinamento e monitoramento do comportamento policial, com destaque para a UE e a Organização para a Segurança e Cooperação na Europa (OSCE), segundo Grillot (2008). Ademais, tais assuntos foram inseridos no processo de adesão à UE, tendo sido avaliados anualmente pela Comissão Europeia.

Entretanto, não se encontrou comprovação de que a UE liderou a dinâmica de formulação de políticas de remodelamento do setor policial, ainda que elas tenham sido elaboradas com base nos modelos policiais europeus e buscando a conformação a esses. A princípio, constata-se que tanto as políticas quanto as práticas que decorrem da SSR policial, manejada no contexto

10 A adesão da Croácia efetivou-se em julho de 2013, momento em que o país se tornou o $28^{\circ}$ Estado membro da UE. 
do SAP em um exercício de europeização, produziram efeitos de absorção de valores da UE e transformação das policies croatas. Tais parecem indicar, no mínimo, a harmonização entre os conteúdos políticos de Croácia e UE, sendo que, em alguns casos, há sinais de convergência entre eles.

Por outro lado, as atividades de defesa foram reformadas em meio a uma dinâmica de pressões e incentivos da OTAN, o que possibilitou à Croácia ser aceita como membro em 2009. Logo, o papel da UE na reforma do setor defensivo deve ser encarado mais como o de um espectador do que propriamente de um ator. A União não estabeleceu condições relativas a assuntos militares nas reformas promovidas no quadro do SAP, até porque as tratativas de admissão do país à OTAN estavam aceleradas durante o processo de adesão à UE (COMISSÃO EUROPEIA COM REPRESENTAÇÃO NA CROÁCIA, 2014).

Em outro sentido, houve um processo de europeização com monitoramento pela UE na reforma dos serviços de inteligência. As elites governantes tiveram papéis fundamentais na construção de estratégias e no remodelamento de políticas e práticas existentes, coordenando a dinâmica de SSR (CVRTILA, 2012). Se, em meados de 2006, podia-se afirmar que a supervisão democrática das atividades de inteligência era inexistente e que elas ainda não funcionavam de acordo com os princípios da UE (CAPARINI, 2006), em 2011, tais serviços já haviam se consolidado como atividades de referência para os vizinhos balcânicos, moldadas a partir dos sistemas de inteligência ocidentais.

No entanto, a maior preocupação durante as negociações de adesão esteve relacionada ao setor judiciário. A SSR do Judiciário foi a mais longa e exigente de todas as reformas no contexto do SAP, o que fez do capítulo 23 do acervo comunitário o último a ser fechado. Ainda que os temas tenham sido considerados satisfatoriamente tratados, a adesão à UE não significa que os desafios terminaram. As legislações, políticas e valores europeus, com efeito, foram absorvidas pelo ordenamento político e legal croata; não obstante, a sua realização prática pode ser diferente (EUROPEAN COMMISSION, 2011a). O país não parece ceder, por exemplo, quanto à punição por crimes de guerra, em especial quando as vítimas foram sérvias e os agressores foram membros das forças securitárias croatas: a maioria desses casos não havia sido levada a julgamento até 2011 (EUROPEAN COMMISSION, 2011a).

A análise das transformações nas SSR croatas demonstra o envolvimento dos atores domésticos em questões que Ihes são mais caras, como a defesa, a inteligência, a polícia e o Judiciário. Isso se deve à credibilidade e ao mérito que a sociedade confere a esses serviços, principalmente por causa do sucesso (para os croatas, é claro) da guerra de independência da Croácia. Como visto, essa dinâmica ocorreu no âmbito do processo de integração europeia, motivo pelo qual se diz que há uma correlação entre este último e as reformas securitárias na Croácia.

\section{Macedônia}

O panorama securitário da Macedônia é delineado por dois fatores: a divisão da sociedade em dois grupos sociais que pouco se conversam (macedônios e albaneses étnicos1) e a presença

11 Indivíduos que ou nasceram na Albânia, ou que nasceram na Macedônia e se consideram albaneses por razão de laços familiares, culturais ou históricos. 
da comunidade internacional por meio de missões de paz. Ao contrário de Croácia, Bósnia e Sérvia, o Estado macedônio não passou por uma transição simultânea do autoritarismo para a democracia e da guerra para a paz. Contudo, o seu setor de segurança também foi moldado por um contexto pós-autoritário (de 1991 a 2001) e outro pós-conflito (de 2001 em diante).

A Macedônia teve sua independência da lugoslávia reconhecida através de negociação, e não de guerra. Logo, na década de 1990, o maior desafio foi a democratização do país e, por conseguinte, das atividades de segurança. No entanto, em 2001, como produto das tensões entre os vizinhos Sérvia e Kosovo, as relações entre macedônios e albaneses étnicos sofreu uma distensão, que resultou em um conflito armado entre insurgentes albaneses e as forças macedônias de segurança. As hostilidades apenas foram amenizadas pela atuação da comunidade internacional, através das operações Essential Harvest, Amber Fox e Allied Harmony (da OTAN), e EUFOR Concordia e EUPOL Proxima (da UE). Essa crise foi o ponto de inflexão que revelou a desorganização dos atores governamentais macedônios quanto à autoridade legal sobre as instituiç̧ões securitárias (CAPARINI, 2006).

A partir disso, o setor de segurança começou a ser reformado com base na assistência de organizações internacionais, como UE, OTAN e OSCE. Nesse sentido, a relação entre o processo de adesão à UE12 e as reformas dos serviços securitários ficou evidente para a representação do bloco europeu na Macedônia (DELEGAÇÃO DA UNIÃO EUROPEIA PARA A ANTIGA REPÚBLICA IUGOSLAVA DA MACEDÔNIA, 2014). Enquanto a UE não participa das reformas de defesa, que seriam tratadas pela OTAN, vislumbra-se sua presença ativa em questões de polícia, inteligência e segurança civil (DELEGAÇÃO DA UNIÃO EUROPEIA PARA A ANTIGA REPÚBLICA IUGOSLAVA DA MACEDÔNIA, 2014).

A conexão da UE à SSR macedônia passa pela preocupação em garantir que existam adequados mecanismos de fiscalização civil sobre o setor de segurança, em especial nas questões de comportamento inadequado da polícia e procedimentos recursais (para que a polícia seja supervisionada por um órgão externo). Ainda, é possível elogiar as reformas nacionais promovidas no âmbito da estrutura e da organização do policiamento, por estarem em consonância com os padrões comunitários, e por sugerirem a aptidão de tais serviços em termos de equipamentos e táticas para lidar com assuntos de segurança interna (DELEGAÇÃO DA UNIÃO EUROPEIA PARA A ANTIGA REPÚBLICA IUGOSLAVA DA MACEDÔNIA, 2014).

Por outro lado, a autoridade do governo macedônio responsável pela parte administrativa do processo de admissão à UE parece confundir segurança e defesa ao negar que o alargamento afete as reformas do setor securitário. Para ele, a UE estaria relacionada apenas à proteção civil ou resolução pós-conflito (SECRETARIA PARA ASSUNTOS EUROPEUS DO GOVERNO DA REPÚBLICA DA MACEDÔNIA, 2014). Contudo, ao afirmar que a UE atua nas questões de proteção civil dentro do processo de adesão, está-se, automaticamente, confirmando a conexão entre SAP e reformas do setor de segurança - as quais não envolvem apenas as atividades militares, mas, também, civis.

\footnotetext{
12 A Macedônia possui o status de Estado Candidato, mas a fase de negociações de adesão ainda não teve início. 0 país apresentou sua candidatura no ano de 2004 e, em 2009, obteve a recomendação da Comissão Europeia para a abertura de negociações. Entretanto, desde então, a Macedônia vem sofrendo o bloqueio da Grécia, a qual, em razão de uma rivalidade política, alega uma disputa de nomenclatura do Estado macedônio como motivo para não aceitar o início das negociações. 0 argumento grego é de que o nome "Macedônia" se refere a uma região grega, que corresponderia ao antigo Império da Macedônia (lar do famoso Alexandre, o Grande), e não ao território do Estado macedônio contemporâneo.
} 
Não obstante, resta à OTAN o papel mais importante em termos de segurança e engajamento militar, conquanto a participação da Macedônia nas missões da OTAN seja bastante ativa, e apesar de esta ainda não ter aderido à Organização por causa do veto da Grécia (SECRETARIA PARA ASSUNTOS EUROPEUS DO GOVERNO DA REPÚBLICA DA MACEDÔNIA, 2014).

De certa forma, os serviços policiais constituem o campo mais delicado em termos de SSR na Macedônia e, portanto, sofrem maior pressão e vigilância por parte da UE e outros atores internacionais. Caparini (2006) destaca a atuação da OSCE no monitoramento, treinamento e introdução de princípios comunitários nos serviços policiais. Por seu turno, a UE implantou três operações: 1) Concordia, durante o ano de 2003, a pedido do governo macedônio, para assegurar a execução do tratado que pôs fim ao conflito iniciado em 2001; 2) Proxima, para ajudar a desenvolver as forças policiais macedônias; e 3) operação de equipe policial consultiva da UE, para apoiar a implementação da reforma policial.

Em alguns momentos, a UE interveio verticalmente na criação ou adaptação de políticas, como na elaboração de diretrizes para o combate da lavagem de dinheiro (através de projeto da Agência Europeia de Reconstrução) ou para a gestão de evidências e análise forense (em projeto financiado pelo Instrumento de Pré-Adesão - IPA, a ferramenta financeira do SAP) (EUROPEAN COMMISSION, 2011b). Em outros, atuou em colaboração com o governo nacional no desenvolvimento de estratégias, como o Conceito de Segurança e Defesa Nacional (aprovada em fevereiro de 2003) (GEORGIEVA, 2007), ou simplesmente proveu assistência técnica ou financeira (como em alguns projetos pelo Twinning, por exemplo, em relação à transferência de competência sobre as fronteiras do setor militar para o policial) (EUROPEAN COMMISSION, 2014b).

Por outro viés, as esferas militar e de inteligência também são motivo de preocupação para a UE, embora, assim como nos demais objetos deste estudo, as reformas no setor defensivo estejam sendo muito mais uma consequência da condicionalidade do processo de adesão à OTAN do que à UE, com o propósito de criar uma força militar pequena, eficiente e moderna. De outro modo, é difícil afirmar que há uma SSR de inteligência em curso. As poucas mudanças que ocorreram nesse setor datam do início dos anos 1990, embora a UE exerça certa pressão em alguns assuntos. Os serviços de inteligência são avaliados no SAP dentro do Capítulo 24, sendo esta a principal forma oficial de a UE exercer pressão.

Por fim, os dados levantados levam à conclusão de que há uma conexão positiva entre reformas do setor securitário e processo de adesão à UE, ainda que isso não se verifique em todos os temas e nem mesmo de forma constante. A UE parece ser instrumental para o reforço das SSR macedônias, visto que continua a ser necessário o desenvolvimento de mecanismos de governança civil e fiscalização democrática sobre as atividades de segurança - e, nesse ponto, a UE, como modelo democrático normativo, pode colaborar. O que importa, aqui, é a sinalização de que algumas transformações securitárias são, sim, impactadas pelos incentivos gerados no quadro da expansão europeia, em direção ao conteúdo europeizante das reformas.

\section{Sérvia}

O principal argumento constatado através de entrevistas com as representações nacional e europeia relacionadas ao processo de adesão da Sérvia à UE é de que, após mais de quinze anos 
de instabilidade política e confusão entre autoritarismo e nacionalismo, o setor securitário sérvio dá sinais de transformações na direção de princípios democráticos.

A resistência às mudanças securitárias na Sérvia perdurou até a queda de Slobodan Milošević, no ano de 2000. Nos anos seguintes, porém, nenhuma reforma foi levada a cabo em função da incerteza política sobre o formato da então lugoslávia. É verdade que o primeiro ministro Zoran Đinđić tentou fazer algumas modificações nesse setor, mas o seu assassinato, em 2003, mostrou que o país não estava pronto para tanto. Naquele momento, a influência das organizações criminosas no governo, na polícia e no campo militar, através de atividades legítimas usadas como fachada ou por meio de subornos, parecia estar consolidada.

Outrossim, tanto a dinâmica de reformas quanto o processo de integração à UE foram retardados pela natureza disfuncional da união entre Sérvia e Montenegro (KOSTOVICOVA, 2014). Depois da separação das duas ex-repúblicas iugoslavas, a Sérvia ainda sofreria com as divergências internas em relação à importância da adesão à UE e do cumprimento das condições estabelecidas para isso, como a cooperação total com o Tribunal Penal Internacional para a exIugoslávia (International Criminal Tribunal for the former Yugoslavia - ICTY). Sem mencionar a disputa pela independência de Kosovo, percebe-se que o contexto mais complicado para a promoção de reformas securitárias, bem como para a expansão europeia, sempre esteve no território sérvio ${ }^{13}$.

Entretanto, a recente abertura da fase de negociações com a Sérvia, em 2014, sugere que tal situação está sendo superada. Segundo a representação do escritório sérvio para a integração à UE, há um bom encaminhamento interno sobre as questões de segurança, sendo que os padrões exigidos já teriam sido alcançados (ESCRITÓRIO SÉRVIO DE INTEGRAÇÃO EUROPEIA, 2014). Como exemplos de condições que foram cumpridas, podem ser citadas: o treinamento de policiais, a elaboração de estratégias e planos de ação contra a corrupção e o terrorismo, e a participação em missões de peacekeeping da UE.

A conexão entre reformas do setor de segurança e processo de adesão fica clara quando é mencionado que a principal vantagem de participar do SAP e da relação de integração com a UE é que tal processo envolve uma dinâmica de condicionalidade em que as obrigações não são estritas, mas sim, de boas práticas (ESCRITÓRIO SÉRVIO DE INTEGRAÇÃO EUROPEIA, 2014). 0 método pelo qual o bloco europeu pressiona os candidatos a adotarem certas medidas seria, na visão da representação sérvia, um "modelo de boa pressão", pois direciona os países a assimilar práticas positivas de gestão em áreas diversas (ESCRITÓRIO SÉRVIO DE INTECRAÇÃO EUROPEIA, 2014).

Dessa maneira, a entrevista com a representação sérvia para a UE permite inferir que, embora não existam obrigações claras no setor militar e de segurança, as boas práticas na condução desses serviços são discutidas dentro do processo de adesão. Pelo mesmo ponto de vista, é argumento da Delegação da UE para a Sérvia de que não existem muitas regras definidas

13 A Sérvia passou por um longo caminho para chegar às negociações de adesão - desde o desinteresse pelo tema até o início da década de 2000, passando pela inércia política e pelo adiamento das tratativas em função da não colaboração com o ICTY, até o lento, mas gradual, progresso nas fases do processo de adesão nos anos mais recentes. O diálogo para a elaboração do SAA teve início em 2005, e em 2009 o país lançou sua candidatura à adesão. Entre o final de 2011 e o início de 2012, o status de Estado Candidato foi garantido, sendo que a fase de negociações foi aberta em 2014. No entanto, ao que tudo indica, este processo será longo, visto que somente terá fim quando o primeiro capítulo aberto das negociações for satisfatoriamente fechado - e ele se refere à normalização das relações entre Sérvia e Kosovo. 
quanto aos assuntos securitários ou SSR no SAP, apesar de haver um benefício implícito na perspectiva de segurança em relação à integração (DELEGAÇÃO DA UNIÃO EUROPEIA PARA A REPÚBLICA DA SÉRVIA, 2014).

Em termos de conteúdo de SSR, algumas políticas de erradicação da corrupção procedem das recomendações do Grupo de Estados contra a Corrupção (GRECO), órgão de monitoramento da corrupção estabelecido pelo Conselho da Europa. Não obstante, o governo elaborou uma Estratégia Nacional de Combate à Corrupção para o período 2013-2018, com base em diretrizes determinadas em avaliações da UE dentro do SAP. Nesse sentido, a Comissão Europeia destaca haver um forte ímpeto político para combater a corrupção, mas os resultados práticos estariam aquém do esperado: o plano de ação da Estratégia estaria sendo procrastinado e os serviços que coordenam e monitoram o plano estariam sendo pouco operantes (EUROPEAN COMMISSION, 2014c).

A esfera policial apresenta transformações recentes. Entre 2006 e 2007, as discussões da Sérvia com a UE sobre o processo de adesão foram suspensas, por causa da falta de cooperação com o ICTY. Após a retomada do diálogo com a UE, as alterações do setor policial aconteceram de forma lenta, não obstante o país evidenciar uma disposição crescente em adequar seu quadro legal para ser admitido no bloco europeu. Houve, por exemplo, a elaboração de uma estratégia chamada Quadro Inicial da Estratégia Nacional de Prevenção ao Crime, em 2009, com base em orientações da Comissão Europeia (DJORDJEVIC, 2010). Contudo, apesar de existir cooperação da Sérvia com instituições da UE e outros organismos internacionais nessas questões, a Comissão Europeia tem avaliado como moderados os resultados alcançados em termos de reforma policial (EUROPEAN COMMISSION, 2010).

Em outro sentido, o ponto de partida para uma reforma séria do setor defensivo deveria ter sido o afastamento de Milošević do poder, no início da década de 2000 (JAZBEC, 2005). Os anos seguintes, porém, foram prejudicados pela ausência de apoio às reformas na arena política. Djurdjevic-Lukic (2007) também argumenta que a falta da priorização das SSR pelos principais atores políticos após a queda de Milošević prejudicou a reforma no período 2000-2006. Depois de 2007, o desmembramento de Sérvia e Montenegro e o incentivo de atores internacionais foram as maiores causas de modificações, instalando-se, assim, um movimento moderado de europeização. Em outubro de 2009, o parlamento sérvio aprovou as últimas leis que faltavam para completar o quadro legal da SSR defensiva (EUROPEAN COMMISSION, 2010).

Quanto à reforma judicial, a Comissão Europeia alerta que a Comissão de Implementação da SSR desta esfera, liderada pelo Ministério da Justiça, não tem atuado de forma proativa, e que existem diversos atrasos na execução de pontos específicos (EUROPEAN COMMISSION, 2014c). Nesse viés, a leitura dos Relatórios de Progresso elaborados pela Comissão Europeia nos últimos cinco anos permite a conclusão de que as reformas têm sido executadas de maneira lenta, o que sugere a falta de interesse dos atores nacionais em realizá-las.

Tendo isso em vista, reconhece-se a necessidade de realização de reformas mais profundas, fundamentada em uma estratégia coerente com os padrões europeus. A avaliação da Comissão é taxativa: os avanços têm sido limitados (EUROPEAN COMMISSION, 2014c), muito embora não se possa negar a existência de um grande esforço europeizante por parte da UE, tanto por meio dos critérios avaliados pela Comissão no curso do processo de adesão, quanto através dos programas e projetos financiados e incentivados. A lentidão para efetivar 
as reformas, porém, contrasta com o esforço cada vez maior do país em progredir no processo de adesão à UE.

\section{Conclusões}

Em síntese, a análise feita nas seções precedentes mostra que Bósnia-Herzegovina, Croácia, Macedônia e Sérvia recebem as sugestões de normatizações europeias de formas variadas, a depender do contexto em que estão inseridas, dos atores políticos em jogo e do conteúdo das reformas.

De fato, a pesquisa qualitativa e as entrevistas realizadas demonstram que há uma influência normativa significativa da UE nas políticas securitárias dos Estados balcânicos ocidentais, ainda que se verifique a presença de outros determinantes, como o papel da OTAN, a dificuldade de governança doméstica e existência de clivagens políticas que podem formar pontos de veto importantes na condução das reformas de segurança.

Apesar disso, é possivel afirmar que há mais resposta positiva do que negativa por parte dos países balcânicos que estão participando (ou já participaram) do processo de integração à União Europeia. Ainda que qualquer influência da UE na formulação de política externa não seja imediatamente visível, precisamente por causa da natureza intergovernamental desse domínio e da ausência de pressão jurídica vinculante nas áreas de policies relativas à segurança e à defesa, a condicionalidade do processo de adesão na formatação dos setores de segurança dos países balcânicos ocidentais evidencia a existência do papel significativo da UE em tal dinâmica.

Não obstante, é verdade que a inserção das regras europeias nas políticas domésticas nem sempre é acompanhada de alterações adequadas nos resultados práticos dessas últimas. Porém, esse fato não deve impedir a conclusão de que as reformas dos setores securitários bósnio, croata, macedônio e sérvio estão vinculadas aos incentivos que a UE promove no quadro do processo de admissão ao bloco.

\section{Referências bibliográficas}

CAPARINI, Marina. Security sector reform in the Western Balkans. DCAF - TESEV Series in Security Sector Studies - 2. 1st Edition: April 2006.

COMISSÃO EUROPEIA COM REPRESENTAÇÃO NA CROÁCIA. Entrevista. Representação da União Europeia para a Croácia. Entrevista concedida à autora em Zagreb, Croácia, em 23/07/2014.

COMMISSION OF THE EUROPEAN COMMUNITIES. Communication from the Commission to the Council and the European Parliament: A Concept for European Community Support for Security Sector Reform. Brussels, 24.5.2006, COM (2006) 253 final. 2006. Disponivel em: <http://eur-lex.europa.eu/legalcontent/EN/TXT/? uri=celex\%3A52006 DC 0253>. Acesso em: 30 de março de 2015.

CVRTILA, Vlatko. Intelligence Governance in Croatia. Strengthening Intelligence Governance in the Western Balkans. DCAF Papers, 2012. 
DELEGAÇÃO DA UNIÃO EUROPEIA PARA A ANTIGA REPÚBLICA IUGOSLAVA DA MACEDÔNIA. Entrevista. Representação da União Europeia para a Macedônia. Entrevista concedida à autora em Skopje, Macedônia, em 08/07/2014.

DELEGAÇÃO DA UNIÃO EUROPEIA PARA A BÓSNIA-HERZEGOVINA E REPRESENTAÇÃO ESPECIAL DA UNIÃO EUROPEIA NA BÓSNIA-HERZEGOVINA. Entrevista. Representação da UE para a BósniaHerzegovina. Entrevista concedida à autora em Sarajevo, Bósnia-Herzegovina, em 21/07/2014.

DELEGAÇÃO DA UNIÃO EUROPEIA PARA A REPÚBLICA DA SÉRVIA. Entrevista. Representação da União Europeia para a Sérvia. Entrevista concedida à autora em Belgrado, Sérvia, em 02/07/2014.

DIRECTORATE FOR EUROPEAN INTEGRATION of the Council of Ministers of Bosnia and Herzegovina. DEl official website 2015. Disponivel em: <http://www.dei.gov.ba/dei/dir ekcija/default.aspx?id=9950\& langTag=en-US>. Acesso em: 30 de março de 2015.

DIRETÓRIO PARA A INTEGRAÇÃO EUROPEIA. Entrevista. Conselho de Ministros da Bósnia-Herzegovina. Representação nacional da Bósnia-Herzegovina. Entrevista concedida à autora em Sarajevo, BósniaHerzegovina, em 21/07/2014.

DJORDJEVIC, Sasa. Fostering the creation of the National Crime Prevention Council. In: MARKOVIC, Z.; DJORDJEVIC, S.; LITAVSKI, J (eds.). Collection of Policy Papers on Police Reform in Serbia. Vol. Number 2. DCAF, March, 2010.

DJURDJEVIC-LUKIC, Svetlana. Defence Reform in Serbia and Montenegro: Hampering Exceptionalism. In: EBNÖTHER, Anja H.; FLURI, Philipp H.; JUREKOVIC, Predrag (eds.). Security Sector Governance in the Western Balkans: Self-Assessment Studies on Defence, Intelligence, Police and Border Management Reform. Vienna and Geneva: DCAF, 2007.

DURSUN-OZKANCA, Oya; VANDEMOORTELE, Antoine. The European Union and Security Sector Reform: current practices and challenges of implementation. European Security, v. 21, n. 2, 2012, p. 139-160.

ESCRITÓRIO SÉRVIO DE INTEGRAÇÃO EUROPEIA. Entrevista. Representação nacional da Sérvia. Entrevista concedida à autora em Belgrado, Sérvia, em 04/07/2014.

EUROPEAN COMMISSION. Serbia 2010 Progress Report accompanying the Communication from the Commission to the Council and the European Parliament Enlargement Strategy and Main Challenges 2010-2011. Commission Staff Working Document. Brussels, 9 November 2010, SEC (2010) 1330. 2010. Disponivel em: <http://ec.europa.eu/enlargement/pdf/key_documents/2010/package/sr_ rapport_2010_en.pdf>. Acesso em: 30 de março de 2015.

EUROPEAN COMMISSION. Croatia 2011 Progress Report Accompanying the document Communication from the Commission to the Council and the European Parliament Enlargement Strategy and Main Challenges 2011-2012. Brussels, 12.10.2011, SEC (2011) 1200 final. 2011. Disponivel em: <http://ec.europa. eu/enlargement/pdf/key_documents/2011/ package/hr_rapport_2011_en.pdf>. Acesso em: 30 de março de 2015. (2011a).

EUROPEAN COMMISSION. The Former Yugoslav Republic of Macedonia 2011 Progress Report Accompanying the document Communication from the Commission to the Council and the European Parliament Enlargement Strategy and Main Challenges 2011-2012. Commission Staff Working Paper. Brussels, 12.10.2011, SEC (2011) 1203 final. 2011. Disponivel em: <http://ec.europa.eu/enlargement/pdf/ key_documents/2011/package/mk_rapport_2011_en.pdf>. Acesso em: 30 de março de 2015. (2011b). 
EUROPEAN COMMISSION. Monitoring Report on Croatia's accession preparations. Communication from the Commission to the European Parliament and the Council. Brussels, 26.3.2013, COM (2013) 171 final. 2013. Disponivel em: <http://ec.europa.eu/archives/commission_2010-2014/fule/docs/news/20130326_ report_final.pdf>. Acesso em: 30 de março de 2015.

EUROPEAN COMMISSION. Bosnia and Herzegovina Progress Report 2014. Commission Staff Working Document. Brussels, COM (2014) 700 final of 8.10.2014. 2014. Disponivel em: <http://ec.europa.eu/ enlargement/pdf/key_documents/2014/20141008-bosnia-and-herzego vina-progress-report_en.pdf>. Acesso em: 30 de março de 2015. (2014a).

EUROPEAN COMMISSION. The Former Yugoslav Republic of Macedonia 2014 Progress Report. Commission Staff Working Document. Brussels, SWD (2014) 303 final of 8.10.2014. 2014. Disponivel em: <http:// ec.europa.eu/enlargement/pdf/key_documents/2014/20141008-the-former-yugoslav-republic-ofmacedonia-progress-report_en.pdf>. Acesso em: 30 de março de 2015. (2014b).

EUROPEAN COMMISSION. 2014. Serbia 2014 Progress Report. Commission Staff Working Document. Brussels, SWD (2014) 302 final of 8.10.2014. Disponivel em: <http://ec.europa.eu/enlargement/pdf/key documents/2014/20140108-serbia-progress-report_en.pdf>. Acesso em: 30 de março de 2015. (2014c).

EUROPEAN UNION. A Secure Europe In A Better World: European Security Strategy. Brussels, 12 December 2003. Disponivel em: <http://www.consilium.europa. eu/uedocs/cmsUpload/78367.pdf>. Acesso em: 30 de março de 2015.

GEORGIEVA, Lidija. Police Reform in Macedonia. In: EBNÖTHER, Anja H.; FLURI, Philipp H.; JUREKOVIC, Predrag (eds.). Security Sector Governance in the Western Balkans: Self-Assessment Studies on Defence, Intelligence, Police and Border Management Reform. Vienna and Geneva: DCAF, 2007.

GRILLOT, Suzette. Policing Via Principles: Reforming the Use of Force in the Western Balkans. East European Politics and Societies v. 22, 2008, p. 319. Disponivel em: http://eep.sagepub.com/ content/22/2/319.full.pdf. Acesso em: 30 de março de 2015.

HÄNGGI, Heiner. Conceptualizing Security Sector Reform and Reconstruction. In: BRYDEN, Alan; HÄNGGI, Heiner (eds.). Reform and Reconstruction of the Security Sector. Münster, Germany: LIT Verlag, 2004.

JAZBEC, Milan. Defence Reform in the Western Balkans: The Way Ahead. Geneva Centre for the Democratic Control of Armed Forces (DCAF) Policy Paper. Geneva, April 2005.

JUNCOS, Ana. Power Discourses and Power Practices: The EU's Role as a Normative Power in Bosnia. In: WHITMAN, Richard (Ed.). Normative Power Europe: Empirical and theoretical perspectives. London: Palgrave, 2011.

KOSTOVIKOVA, Denisa. When Enlargement Meets Common Foreign and Security Policy: Serbia's Europeanisation, Visa Liberalisation and the Kosovo Policy. Europe-Asia Studies, Vol. 66, No. 1, January 2014, 67-87. Disponivel em: http://eprints.Ise.ac.uk/54972/. Acesso em: 30 de março de 2015.

RADAELLI, Claudio. The domestic impact of European Union public policy: Notes on concepts, methods, and the challenge of empirical research. Politique européenne, $n^{\circ}$ 5, 2002/1, p. 105-136. Disponivel em: www.cairn.info/revue-politique-europeenne-2002-1-page-105.htm. Acesso em: 30 de março de 2015.

RADAELLI, Claudio. The Europeanization of Public Policy. In: FEATHERSTONE, Kevin; RADAELLI, Claudio (eds.). The Politics of Europeanization. Oxford: Oxford University Press, 2003. 
RYAN, Barry J. The EU's Emergent Security-First Agenda: Securing Albania and Montenegro. Security Dialogue v. 40, 2009, p. 311. Disponivel em: http://sdi.sagepub.com/content/40/3/311.short. Acesso em: 30 de março de 2015.

SECRETARIA PARA ASSUNTOS EUROPEUS DO GOVERNO DA REPÚBLICA DA MACEDÔNIA. Entrevista. Representação nacional da Macedônia. Entrevista concedida à autora em Skopje, Macedônia, em 08/07/2014.

SELLTIZ, Claire et al. Métodos de pesquisa nas relações sociais. 2ª ed. São Paulo: EPU. 1987.

STOJAROVA, Vera. Organized Crime in the Western Balkans. HUMSEC Journal, Issue 1, 2007. Disponivel em: http://www.humsec.eu/cms/fileadmin/user_upload/humsec/Journal/ Stojarova_Organized_Crime_ in_the_Western_Balkans.pdf. Acesso em: 30 de março de 2015. 